\title{
Relationship Between Sources of Information and the Willingness of Healthcare Workers to Risk their Lives for a Patient During the Peak of A/H1N1 Pandemic in Israel ${ }^{\S}$
}

\author{
Yaron Bar-Dayan ${ }^{*}, 1,2$, Sarit Natan Manor ${ }^{1}$, Noga Boldor ${ }^{1,3}$, Inbar Kremer ${ }^{1}$, Maya Iohan Barak ${ }^{1}$ and \\ Yosefa Bar-Dayan ${ }^{4,5}$ \\ ${ }^{I}$ Department of Management, Bar Ilan University, Israel \\ ${ }^{2}$ Faculty of Health Sciences, Ben Gurion University, Israel \\ ${ }^{3}$ Israeli Center for Technology Assessment in Health Care, The Gertner Institute for Epidemiology and Health Policy \\ Research, Tel Hashomer, Israel \\ ${ }^{4}$ Faculty of Medicine, Tel Aviv University, Israel \\ ${ }^{5}$ Interdisciplinary Department of Social Sciences, Bar Illan University, Israel
}

\begin{abstract}
Background: The willingness of healthcare workers to risk their lives for a patient if a fatal transformation of the virus would occur is a major concern, especially during a pandemic where the need for adequate staffing is crucial and where the public atmosphere might increase anxiety and fear of exposure.

Objective: To examine the relationships between the source of information about the disease and the willingness of healthcare workers to risk their lives for a patient with a fatal A/H1N1 flu, during the winter A/H1N1 pandemic in Israel.

Methods: A questionnaire was distributed to healthcare workers in 21 hospitals and 40 primary clinics in Israel between November 26, 2009 and December 10, 2009 (the peak of the winter A/H1N1 flu outbreak).

Results: The questionnaire was completed by 1147 healthcare workers. The most common source of information reported was television (65\%), followed by speaking with colleagues and reading the Ministry of Health regulations $(63 \%)$ each, internet $(61 \%)$, and newspapers $(51 \%)$. The least common sources of information were reading a scientific article $(35 \%)$ and attending a professional lecture (31\%). Willingness to risk one's life was significantly higher in healthcare workers who reported that their source of information about the disease was reading a scientific article, Ministry of Health regulations, a professional lecture, or a colleague. Willingness was not significantly different among health care workers who reported that their source of information about the disease was television programs, a newspaper article, or general internet sites.
\end{abstract}

Conclusions: Willingness to risk one's life for a patient is directly related to professional sources of information and is not related to nonprofessional information obtained from mass media.

Keywords: Healthcare workers, willingness, sources of information, H1N1 flu.

\section{INTRODUCTION}

In March 2009, the World Health Organization (WHO) declared an A/H1N1 influenza pandemic. On June 11, 2009, the WHO declared a global pandemic and by November 12, 2009, 7,487 people had died from the disease [1]. In Israel, between April and October 2009, 4,607 patients were diagnosed with $\mathrm{A} / \mathrm{H} 1 \mathrm{~N} 1$ influenza, 85 of whom were hospitalized in intensive care units. The first verified flu death was reported on July 25 , 2009 and by November 5, 2009, 40 deaths had occurred, most in patients with a chronic disease [2].

*Address correspondence to this author at 16 Dolev St. Or Yehuda, Israel; Tel: 00972578186215; E-mail: bardayan@netvision.net.il

${ }^{\S}$ This study was a part of the requirements of the Master Degree Thesis, conducted by Noga Boldor, directed by Professor Yaron Bar-Dayan, in the Department of Management, the Faculty of Social Sciences, Bar Ilan University, Givat Shmuel, Israel.
Although a high percentage of healthcare workers feel an obligation to work during an influenza pandemic, barriers to working may significantly reduce the number of workers during a pandemic. Barriers to willingness include fear and concern for family and self, and personal health problems, many of which are amenable to intervention [3]. Other parameters related to willingness to attend work during a pandemic flu are sense of security, professional commitment, perceived professional competence, and trust in employers [4]. Another study found that willingness was related to provision of accommodations, information and guidance by employers [5], as well as the availability of appropriate personal protection equipment and a comprehensive education and training plan [6-8]. However, absenteeism may be reduced by taking educative steps to prevent 'barriers to willingness' from becoming perceived 'barriers to ability' [5]. 
To prepare for a pandemic response, the issues that may affect the decision not to attend work must be identified. This is especially important because in many countries healthcare workers can not be forced by the law to attend work. In one report, up to $16 \%$ of healthcare workers stated they would not attend work during a pandemic flu regardless of its severity [6]. A study in Germany reported that $28 \%$ of a sample of healthcare workers said that it would be professionally acceptable for healthcare workers to abandon their workplace during a pandemic to protect themselves and their families [9].

A recent study describing the sources of information of the population during an avian influenza outbreak reported that the frequency of use of sources of information by the population during the early phase of a bird flu outbreak in Israel differed between the affected area and the general population [10]. Another study reported that the sources of information concerning a terrorist suicide bomber attack, the level of knowledge concerning the event, and acquaintance with authorities' instructions differed significantly between the inner circle and the public [11]. It was suggested that authorities must pay attention to this phenomenon and provide information appropriate to each area in order to better achieve the desired behavior among the population during a disease outbreak or a terrorist bombing attack $[10,11]$.

The willingness of healthcare workers to risk their lives for a patient if a fatal transformation of the virus would occur is a major concern, especially during a pandemic where the need for adequate staff is crucial and the public atmosphere might increase anxiety, fear, and unwillingness to work.

This study examined the relationship between the sources of information about the disease and the willingness of healthcare workers to risk their lives for a patient with a fatal A/H1N1 flu.

\section{METHODS}

\section{Instrument and Key Measures}

Based on a review of the literature [10-12], we hypothesized that using professional sources of information such as reading a scientific article, instructions from the Ministry of Health $(\mathrm{MOH})$, attending a professional lecture, or speaking with a colleague, would be positively related to the willingness of healthcare workers to risk their lives for a patient if a fatal transformation of $\mathrm{A} / \mathrm{H} 1 \mathrm{~N} 1$ virus would occur. We selected and validated a questionnaire based on this model and on prior research [10,11], to assess the relationships between willingness, and different sources of information about the disease. The questionnaire was validated for content and structure. Inter-observer and intraobserver variability of each questionnaire item was very low and the internal consistency coefficient was 0.7-0.9. The questionnaire included open and multiple-choice questions and questions on a 5-point Likert scale where 5 was "very high" and 1 was "very low". Assessment of the willingness to risk one's life was obtained by the question "If the $\mathrm{A} / \mathrm{H} 1 \mathrm{~N} 1$ virus transforms to a fatal strain, to what extent will you be willing to risk your life and treat a patient, knowing that a colleague who was infected by this patient had died from the disease?". Assessment of the level of use of each source of information was obtained by the question "To what extent did you get information concerning $\mathrm{A} / \mathrm{H} 1 \mathrm{~N} 1$ influenza from each of the following sources of information: televison, newspaper, internet, reading a scientific article, reading the $\mathrm{MOH}$ regulations, attending a professional lecture, or speaking with a colleague?".

\section{Population}

The study was conducted between November 26, 2009 and December 10, 2009. A sample of healthcare workers in 21 general hospitals and 40 primary care clinics in Israel who attended work during the study period and who were older than 18 years of age were asked to complete the questionnaire.

\section{Data Collection}

The survey was conducted by healthcare workers with relevant academic education in health systems management and public health, who were trained in providing informed consent and questionnaire administration. The study was approved by the institutional review board of Bar Ilan University. The questionnaires were completed at the workplace, immediately and privately, and returned to the researchers without any subject identifiers. Questionnaire data were entered into an SPSS file and triple-checked to ensure accuracy.

\section{Statistical Analysis}

The relationships between the sources of information and the willingness of healthcare workers to risk their lives for a patient in case a fatal transformation of the virus would occur were analyzed. For data analysis, 'willingness to risk life' was categorized either as very high/high, or moderate/ low/very low. Participants who graded their willingness to treat the patient as 'very high or high' were considered 'willing to risk his or her life.' Differences between groups were analyzed using the chi-square test for fit independence. A P value of $<0.05$ was considered significant. In addition, multivariate logistic regression was conducted, to adjust for confounding variables (sex, age, marital status, education, profession, workplace, hospital or primary care clinic, professional experience, mass media as the source of information and professional sources of information), in order to predict the willingness of healthcare workers to risk their lives for a patient. The goodness-of-fit of the model was tested using the Hosmer-Lemeshow test [14]. The Area Under the Curve (AUC) was calculated as an indicator of the prediction performance of the model.

\section{RESULTS}

The research took place in 21 hospitals and 40 primary care clinics in Israel. Questionnaires took 8 to 12 minutes to complete. A total of 1147 questionnaires were answered by healthcare wokers, including $16 \%$ physicians, 39\% nurses, $25 \%$ paramedical staff, $13 \%$ administrative staff, and $8 \%$ other professions. The refusal rate was less than $5 \%$. The mean age of the population ( \pm standard deviation) was $41 \pm 11$ years, $68 \%$ were female, $72 \%$ married and $69 \%$ had childcare responsibilities with a mean of $1.5 \pm 1.4$ children each. Participants had an average of $17 \pm 3$ years of education and $16 \pm 11$ years of professional experience. 


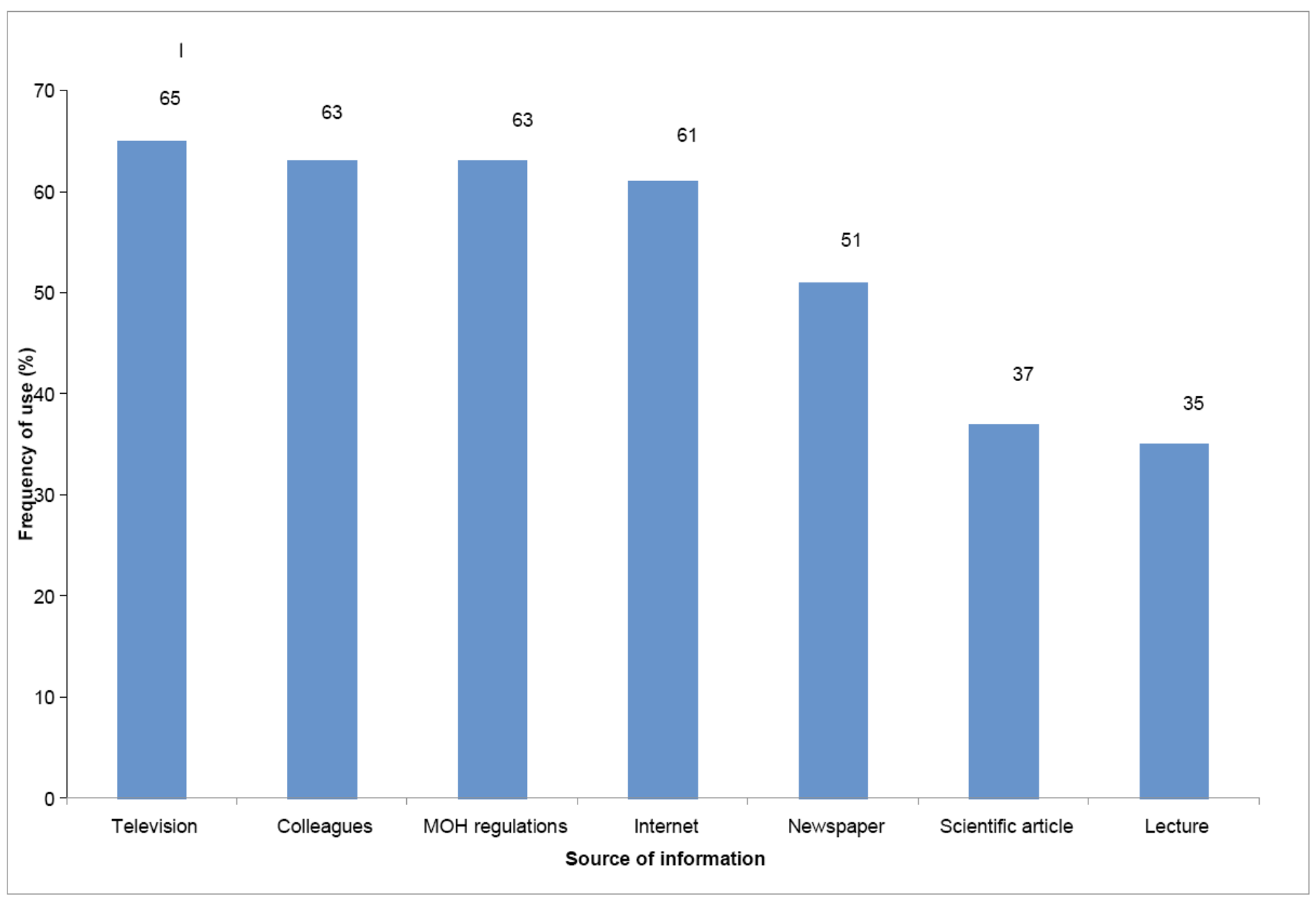

Fig. (1). Frequency of use of different sources of information by health care workers at the peak of A/H1N1 pandemic in Israel.

The most common source of information reported by the healthcare workers was television $(65 \%)$, followed by speaking with colleagues and reading $\mathrm{MOH}$ regulations $(63 \%)$, internet (61\%), and newspapers (51\%). The least common sources of information were reading a scientific article (35\%) and attending a professional lecture (31\%; Fig. 1).

Eighty-four percent of healthcare workers who read a scientific article about $\mathrm{A} / \mathrm{H} 1 \mathrm{~N} 1$ flu were willing to risk their lives for a patient compared with $73 \%$ of healthcare workers who had not read an article $(\mathrm{P}<0.001$; Fig. 2). Healthcare workers who were acquainted with the $\mathrm{MOH}$ regulations concerning $\mathrm{A} / \mathrm{H} 1 \mathrm{~N} 1$ flu were significantly more willing to risk their lives for a patient compared with healthcare workers who were not $(82 \%$ vs $69 \%$, respectively, $\mathrm{P}<0.001)$. Similarly, healthcare workers who attended a lecture about $\mathrm{A} / \mathrm{H} 1 \mathrm{~N} 1 \mathrm{flu}$ were significantly more willing to risk their lives for a patient compared with healthcare workers who did not attend a lecture ( $84 \%$ vs $73 \%$, respectively, $\mathrm{P}=0.001)$. Speaking with colleagues about A/H1N1 flu was positively related to willingness to risk one's life for a patient $(80 \% v s$ $71 \%, \mathrm{P}=0.002$ ). No significant differences in the willingness to risk their lives were found between healthcare workers who gained information about the disease from lay sources including television, newspapers and internet.

The variables listed in Table $\mathbf{1}$ were entered into a multivariable logistic regression. The reference groups for the categorical variables profession and marital status were physician and bachelor respectively. The variable "mass media" was calculated as the average of the variables "television", "newspapers" and "internet". Similarly, the variable "professional sources" was calculated as the average of the variables "speaking with colleagues", "professional lecture", "scientific article" and "Ministry of Health regulations".

The logistic regression model showed that the following factors were statistically significant: professional sources $(O R: 1.24(1.02-1.51), P=0.033)$, workplace

(OR: $0.593(0.361-0.973), P=0.039)$. Professional categories $(P<0.0001)$ : paramedical staff

(OR: $0.335(0.156-0.721), P=0.005)$, administrative staff (OR: $0.246(0.099-0.614), P=0.003)$, other professions (e.g. secretaries, social workers)

(OR: $0.162(0.061-0.428), P<0.0001)$.

All other factors did not reach statistical significance $(P>0.05)$. To verify the goodness-of-fit of the proposed model, the Hosmer-Lemeshow test was conducted and was 


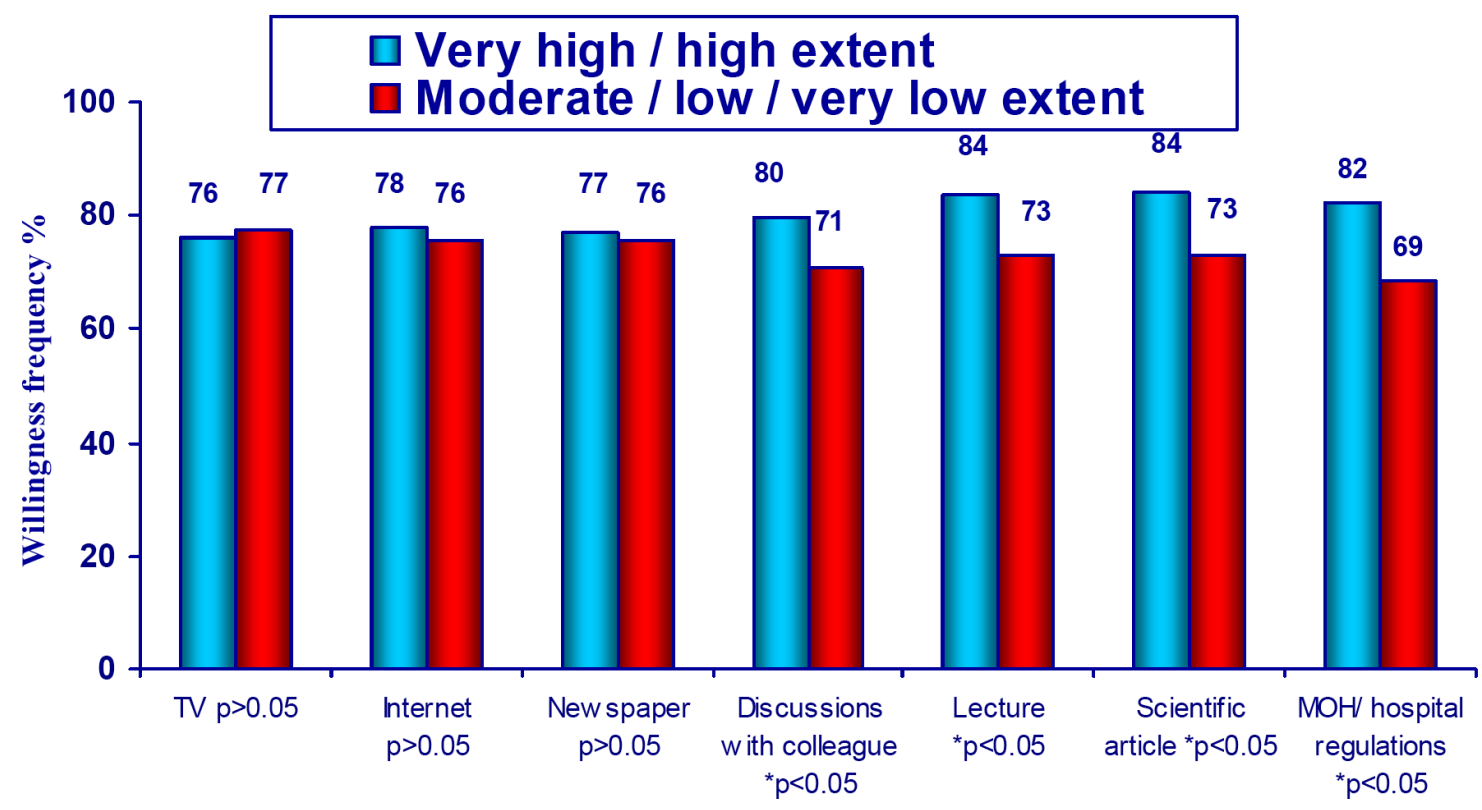

To each source of information

Fig. (2). Frequency differences according to the extent of exposure to source of information among healthcare workers reporting high/very high willingness to treat patients suffering from a lethal, infectious disease $(*=$ significant differences).

far from significant $\left(\chi_{8}^{2}=13.229, P>.05\right)$, which indicates good reliability. The Area Under the Curve (AUC) is an indicator for prediction performance of the model and the largest AUC, varying from 0.5 to 1.0 , is the most ideal model, in this model AUC $=0.723$.

Table 1. Logistic Regression Predicting Willingness of Health Care Workers to Risk Lives for a Patient During the Peak of A/H1N1 Pandemic in Israel

\begin{tabular}{|l|c|c|}
\hline \multicolumn{1}{|c|}{ Variables } & OR (95\% CI) & P-Value \\
\hline \hline Sex (female) $(n=1107)$ & $0.904(1.361-0.6)$ & .629 \\
\hline Age $(n=1120)$ & $1.013(1.055-0.973)$ & .519 \\
\hline Marital status (bachelor) $(n=204)$ & & .443 \\
\hline Marital status (married) $(n=812)$ & $0.875(1.432-0.534)$ & .595 \\
\hline Marital status (divorced) $(n=98)$ & $0.927(1.992-0.432)$ & .846 \\
\hline Marital status (widowed) $(n=18)$ & $0.302(1.278-0.071)$ & .104 \\
\hline Education $(n=1086)$ & $1.079(1.174-0.992)$ & .078 \\
\hline Profession (physicians) $(n=177)$ & & $<0.0001$ \\
\hline Profession (nurse) $(n=440)$ & $0.569(1.189-0.272)$ & .134 \\
\hline Profession (paramedical staff) $(n=278)$ & $0.335(0.721-0.156)$ & .005 \\
\hline Profession (administrative staff) $(n=159)$ & $0.246(0.614-0.099)$ & .003 \\
\hline Profession (other professions) $(n=90)$ & $0.162(0.428-0.061)$ & $<0.0001$ \\
\hline Workplace (clinics) $(n=1145)$ & $0.593(.973-0.361)$ & .039 \\
\hline Professional experience $(n=1081)$ & $1.011(1.052-0.972)$ & .583 \\
\hline Mass media $(n=1126)$ & $1.006(1.223-0.828)$ & .948 \\
\hline Professional sources $(n=1124)$ & $1.239(1.508-1.017)$ & .033 \\
\hline
\end{tabular}

\section{DISCUSSION}

This study demonstrated that the most common sources of information used by healthcare workers at the peak of the A/H1N1 pandemic in Israel were television, Ministry of Health regulations, speaking with colleagues, and searching the internet. Gaining information from professional sources was directly related to the willingness to risk their lives for a patient in case of a fatal transformation of the virus.

Studies concerning sources of information during a disaster or emergency event have been conducted among the general population. It was reported that populations vary in their frequency of using different sources of information during a disaster [10,11]. During the avian influenza outbreak in Israel, television was the most frequently used source of information by the general population, whereas in affected areas, people obtained information from friends and local authorities significantly more often [10]. Television, newspapers, and healthcare providers were reported to be the most preferred sources of information concerning the A/H1N1 pandemic [12].

A study surveyed the use of YouTube videos with relevant information about $\mathrm{A} / \mathrm{H} 1 \mathrm{~N} 1$ influenza by internet users and found that $61.3 \%$ of videos had useful information about the disease, whereas $23 \%$ were misleading. Total viewership share of useful videos was $70.5 \%$, whereas that of misleading videos was $17.5 \%$. The authors concluded that YouTube provided a substantial amount of useful information about $\mathrm{A} / \mathrm{H} 1 \mathrm{~N} 1$ influenza [13].

This study is limited in that we used a sample of healthcare workers who attended work the day the questionnaire was distributed. This could have biased the results because healthcare workers who did not attend work during the peak of the pandemic were not surveyed. However, attendance at work was very high (>95\%) during the study period and the sample was large. Therefore, we believe that the results represent Israeli healthcare workers. 
Another possible limitation of the study derives from the fact that the questionnaire measured the self-reported willingness, which could be related to education, and therefore, could lead to a differential bias.

This study provides a comprehensive evaluation of the relationships between the sources of information about a disease and the willingness of healthcare workers to risk their lives for a patient in case a fatal transformation of the virus occurs. The results of the study provide healthcare managers with data concerning how frequently healthcare workers used each source of information at the peak of the pandemic. This can be used to help focus efforts at disseminating information towards the most frequently used sources. The provision of health information should be directed toward meeting the needs of healthcare workers. The fact that different sources of information are related to differences in the willingness of healthcare workers to risk their lives should be used when health system policy makers prepare campaigns directed toward healthcare workers during the peak of a pandemic.

We conclude that the willingness to risk one's life for a patient is related to obtaining information from professional sources and not from lay information provided by mass media. Authorities must pay attention to this phenomenon and provide suitable sources of information to ensure that healthcare workers are exposed to the desired information. This method of assessment is recommended to improve both evidence-based decision making of health policy makers and disaster preparedness.

\section{ACKNOWLEDGEMENTS}

The authors are indebted to Faye Schreiber, MS for English revisions to the manuscript.

\section{REFERENCES}

[1] World Health Organization. http://www.who.int/csr/disease/swine flu/en/index.html, A/H1N1 pandemic flu [Accessed: 24.2.2010].
[2] Israel Ministry of Health, the division of disaster and emergency preparedness and response. http://www.health.gov.il/h1n1/world. asp [Accessed: 24.2.2010].

[3] Qureshi K, Gershon RR, Sherman MF, et al. Health care workers ability and willingness to report to duty during catastrophic disasters Jr Urban Health. Bull N Y Acad Med 2005; 82(3): 37888 .

[4] Smith E. Paramedics perception of risk and willingness to work during conventional and non-conventional disasters. Presented at the Australian College of Ambulance Professionals (ACAP) Nat Conf Adel Australia 2006

[5] Ives J, Greenfield S, Parry JM, et al. Healthcare workers attitudes to working during pandemic influenza: A qualitative study. BMC Pub Health 2009; 12(9): 56.

[6] Barnett DJ, Balicer RD, Thompson CB, et al. Assessment of local public health workers' willingness to respond to pandemic influenza through application of the extended parallel process model. PloS One 2009; 4(7): e6365.

[7] Shapira Y, Marganitt B, Roziner I, Shochat T, Bar Y, Shemer J. Willingness of staff to report to their hospital duties following an unconventional missile attack: A state wide survey. Isr J Med Sci 1991; 27: 704-11.

[8] Koh D, Lim MK, Chia SE, et al. Risk perception and impact of SARS on work and personal lives of healthcare workers in Singapore - what can we learn? Med Care 2005; 43: 676-682.

[9] Ehrenstein B, Hanses F, Salzberger B. Influenza pandemic and professional duty family or patients first? A survey of hospital employees. BMC Public Health 2006; doi:10.1186/1471-2458-6311.

[10] Peltz R, Avisar SG, Ventura-Gabay M, Bar-Dayan Y. Differences in the sources of information used by the population between the affected area and the nationwide general population during the first phase of a bird flu outbreak in Israel. Prehosp Disaster Med 2008; 23 (1): 57-9.

[11] Richman A, Shohat G, Soffer Y, Bar-Dayan Y. Differences in sources of information and acquaintance with instructions between Dimona and the general population after a suicide bomber event. Prehosp Care Disaster Med 2010; 25 (1): 55-8.

[12] Wong LP, Sam IC. Public sources of information and information needs for pandemic Influenza A (H1N1) J Commun Health 2010; [Epub ahead of print].

[13] Pandey A, Patni N, Singh M, Sood A, Singh G. YouTube as a source of information on the H1N1 influenza pandemic. Am J Prev Med 2010; 38 (3): e1-3.

[14] Hosmer DW, Lemeshow S. Applied logistic regression. New York: John Wiley \& Sons, Inc 1989. 